\title{
Benchmarking supply chain management practices in a South African confectionery manufacturing organisation
}

\begin{abstract}
Authors:
Orestes Peristeris ${ }^{1,2}$

Peter J. Kilbourn ${ }^{2}$

Jacobus Walters ${ }^{2}$

Affiliations:

${ }^{1}$ Strategic Operations, Value

Logistics, South Africa

${ }^{2}$ Department of Transport

and Supply Chain

Management, University of

Johannesburg, South Africa

\section{Correspondence to}

Orestes Peristeris

Email:

operisteris@gmail.com

Postal address:

PO Box 441, Paardekraal

1752, South Africa

Dates:

Received: 15 Mar. 2015

Accepted: 17 June 2015

Published: 14 Aug. 2015

How to cite this article:

Peristeris, O., Kilbourn, P.J. \& Walters, J., 2015,

'Benchmarking supply chain management practices in a South African confectionery manufacturing organisation' Journal of Transport and Supply Chain Management 9(1), Art. \#179, 10 pages. http://dx.doi.org/10.4102/ jtscm.v9i1.179

\section{Copyright:}

(C) 2015. The Authors. Licensee: AOSIS

OpenJournals. This work is licensed under the Creative Commons Attribution License.
\end{abstract}

Read online:
Background: In an increasingly competitive business world, businesses need to be able to measure the effectiveness of their supply chain management process practices against proven best practice frameworks. A number of these frameworks exist internationally but have to be used within the context of knowing the relative strengths and weaknesses of potential benchmarking frameworks. Two such frameworks were identified in the research and a case was made to use one such framework, the Global Supply Chain Forum (GSCF) framework, to measure the effectiveness of the supply chain practices of a leading confectionery manufacturing company in South Africa.

Objective of the research: The purpose of the research was to identify an international best practice framework, which could be used by South African manufacturing organisations to benchmark their supply chain management (SCM) practices.

Methodology: The methodology followed was a literature review of the existing SCM frameworks to identify a framework, which would be the most suited to the objective of the study, followed by a case study of a leading manufacturing organisation's SCM practices benchmarked against those found in the framework.

Results and conclusions: The main finding of the case study was that there is a high degree of adherence between the case study organisation's SCM practices and those found in the SCM framework. There was also generally a high level of importance ascribed by respondents to the best practices contained by the GSCF framework. It was therefore concluded that the GSCF framework proved to be a useful instrument for a comprehensive analysis of supply chain management processes and practices for a manufacturer in the fast moving consumer goods industry, with potential for applications by organisations in the supply chains of other industries.

\section{Introduction}

The South African confectionery industry is a very competitive industry for the three major manufacturers dominating the scene. Not only do they have to compete with one another as well as a large number of medium size and small enterprises, they also have to compete against lowcost producers and imported product from emerging countries such as China, Brazil, Turkey and Malaysia.

There is a growing body of evidence in the literature regarding the impact that supply chain management (SCM) has on the ability of a business organisation to create a competitive advantage for itself and other supply chain members in the industry it operates in. A logical assumption is that SCM increases in importance where organisations find themselves in a very competitive industry.

In academic literature, it is ordinarily proposed that efficient and effective SCM requires the integration of cross-functional and cross-entity activities in the supply chain. As a result, the management of internal and external relationships is also a key requirement for SCM success.

Consistent with the need for the integration of activities across a supply chain, a process approach is increasingly proposed as the desired way for the management of supply chain activities. Supply chain processes commonly are cross-functional in nature and the management thereof requires an approach different to the traditional functional or silo-based managerial approach. It is also required that organisations have a supply chain strategy and that the strategy be well aligned with both the corporate strategy and other functional strategies. Without this alignment, the cross-functional implementation of supply chain activities will be problematic and may result in suboptimal outcomes. 
In order for an organisation to manage effectively its supply chain, an in-depth understanding of the SCM concept, and how it is carried out in practice, is required. In addition, it is important to regularly review and benchmark supply chain processes and practices against available best practice frameworks.

Based on existing research propositions, this framework will have to be oriented towards cross-functional and cross-entity processes and relationships, and be guided by strategic and operational level strategies and benchmarks. In addition, the framework will have to be well tested and supported in industry. The purpose of the study was to identify a best practice SCM framework, which complies with these requirements, and to evaluate the SCM activities of a leading South African manufacturer against it to determine whether such a framework could be applied to a South African business.

This article is based on the research conducted for the dissertation based master's degree study undertaken at the University of Johannesburg entitled Supply Chain Management Practices in a Leading Manufacturing Organisation.

\section{Literature review}

\section{Supply chain management and competitive advantage}

A large number of definitions of SCM have been published over time, both in the academic literature and by professional associations concerned with operations, logistics, and supply chain management. From many definitions, this study identified two definitions which, when read together, encapsulates the very essence of SCM:

The management of a network of relationships within an organisation and between interdependent organisations and business units consisting of material suppliers, purchasing, production facilities, logistics, marketing, and related systems that facilitate the forward and reverse flow of materials, services, finances and information from the original producer to final customer with the benefits of adding value, maximising profitability though efficiencies, and achieving customer satisfaction. (Stock \& Boyer 2009:706)

The integration of key business processes from end user through original suppliers that provides products, services and information that add value for customers and other stakeholders. (Lambert, Cooper \& Pagh 1998:1)

These definitions reflect a number of aspects that are fundamental to the understanding of SCM:

- the management of relationships amongst independent organisations and functions

- the involvement of functions outside the scope of logistics management

- the flow of finances and information in addition to raw material and finished goods

- the creation of value in order to maximise profitability whilst achieving customer satisfaction

- the integration of business processes across multiple organisations in the supply chain.
Competitive advantage is based on the value an organisation can create for its customers that exceeds the organisation's costs of creating it (Porter 1985:3) and a sustainable advantage allows it to earn profits that are above the industry average (Ritala \& Ellonen 2010:376). SCM capabilities are an important determinant of business performance and competitive advantage and have a direct and indirect effect on perceived product value, customer loyalty, market performance, and financial performance (Tracey, Lim \& Vonderembse 2005:178). The benefits of effective SCM has been recorded as the marketing of unique products and services, faster research and development (R\&D) cycle times, superior quality, cost competitiveness, shorter order cycles, flexible customer response, enhanced delivery performance, improved asset management, shorter cash-to-cash cycles, and superior relationships with supply chain members (Fawcett, Magnan \& McCarter 2008:35).

Successful supply chain integration has a positive influence on supply chain performance and competitive capability (Bagchi et al. 2005:275; Kim 2006:241; Lin \& Chen 2008:83). However, these benefits can only be realised if the connections and inter-relationships amongst the different entities in the supply chain are recognised and effectively managed. Therefore, what is required for organisational performance improvement is close strategic alignment and coordination with supply chain partners (Kim 2006:247). Evidence exist that the higher the level of integration with customers and suppliers in the supply chain the greater the potential benefits, and that organisations that integrated with a greater number of customers and suppliers saw the largest rates of performance improvement (Zailani \& Rajagopal 2005:379).

Supply chain management is implemented by integrating major business functions and business processes within and across organisations in the supply chain (Bagchi et al. 2005:275; Chen, Daugherty \& Roath 2009:63; Council of Supply Chain Management Professionals 2014; Lambert, García-Dastugue \& Croxton 2005:379). It includes business processes that cut across organisational boundaries and functional areas such as logistics, marketing, finance and manufacturing (Lambert et al. 2005:25).

\section{Fundamental challenges in supply chain management}

SCM practitioners need clarity about the scope of processes to include in their integration plans, the individuals and entities to involve, the methodologies to follow as well as key performance areas to focus on in the measurement of performance. This opinion is supported by Lambert (2008:2) who states that there is a need for broadly accepted normative tools and methods for SCM practice.

Process-oriented supply chain management frameworks An evaluation conducted by Lambert et al. (2005:25) of process-oriented SCM frameworks resulted in the 
identification of five frameworks, each with its distinctive characteristics and objectives. For the purpose of this study only two frameworks justified closer examination, namely the framework developed by the Global Supply Chain Forum (GSCF) and the Supply Chain Council's (SCC) SCOR (Supply Chain Operations Reference model). The main reasons for this are that these frameworks could be used by the management of an organisation to achieve cross-functional integration as they contain sufficient detail on processes and best practices to be implemented within a business environment. Lambert et al. (2005:25) also found that both the GSCF and SCOR models were the only frameworks found to be supported by major corporations. The following sections will discuss these two frameworks in more detail:

- The SCOR model: The SCOR model is defined as a standardised process model that provides a standardised description of the processes found in a supply chain, which enables the analysis, comparison, and evaluation of supply chains between different companies and different industries (Poluha 2007:49). According to the SCC, the SCOR model was published to describe the supply chain in multiple levels of detail, identify best practices, and define associated key performance indicators (KPIs) for each process, and to provide a basis for consensus on terminology, processes, and expectations amongst trading partners (Poluha 2007:49).

The SCOR model is described as having three primary applications: to assess and compare supply chains' performance potential, to analyse and optimise integrated supply chains, and to determine suitable places for the utilisation of software functionality within the supply chain. The logic behind the SCOR model is premised on the supply chain and logistics network being described using five fundamental processes: plan, source, make, deliver, return (Poluha 2007:49; Supply Chain Council 2011:1.2.1).

- The GSCF framework: The GSCF defines SCM as 'the integration of key business processes from end user through original suppliers that provides products, services, and information that add value for customers and other stakeholders' (Lambert et al.1998:1). Implementation is carried out through three primary elements and key decision areas: the supply chain network structure, the supply chain business processes, and the management components. The supply chain network structure consists of the member organisations to which key processes will be linked. The supply chain management components determine what level of integration and management should be applied for each process link. The decision associated with the supply chain business processes involves which processes should be linked with each of the key supply chain members identified as forming part of the supply chain network.

The GSCF identifies eight key processes that constitute the core of supply chain management: customer relationship management, customer service management, demand management, order fulfilment, manufacturing flow management, supplier relationship management, product development and commercialisation, and returns management. Customer relationship management and supplier relationship management are the critical links in the supply chain to an organisation's customers and suppliers, with the other six processes being co-ordinated through them.

For the purpose of this study, the two frameworks were analysed in detail, and compared according to their scope, strategic alignment, breadth of activities, cross-functional involvement, process and performance benchmarking, and the measurement of value creation. The relative strengths and weaknesses of the frameworks were also identified. Table 1 sets out the distinct characteristics of the two frameworks.

On the basis of the research carried out by Lambert et al. (2005:25) and the authors' analysis and evaluation of the GSCF and SCOR frameworks, it is found that the SCOR framework focuses on creating operational process excellence within the context of the supply chain, and the GSCF framework provides a model for generating significant benefits through strategically managing interorganisational collaborative processes in the supply chain. The criteria are taken from the study conducted by Lambert et al. (2005:25).

TABLE 1: Comparison between Supply Chain Operations Reference and Global Supply Chain Forum frameworks.

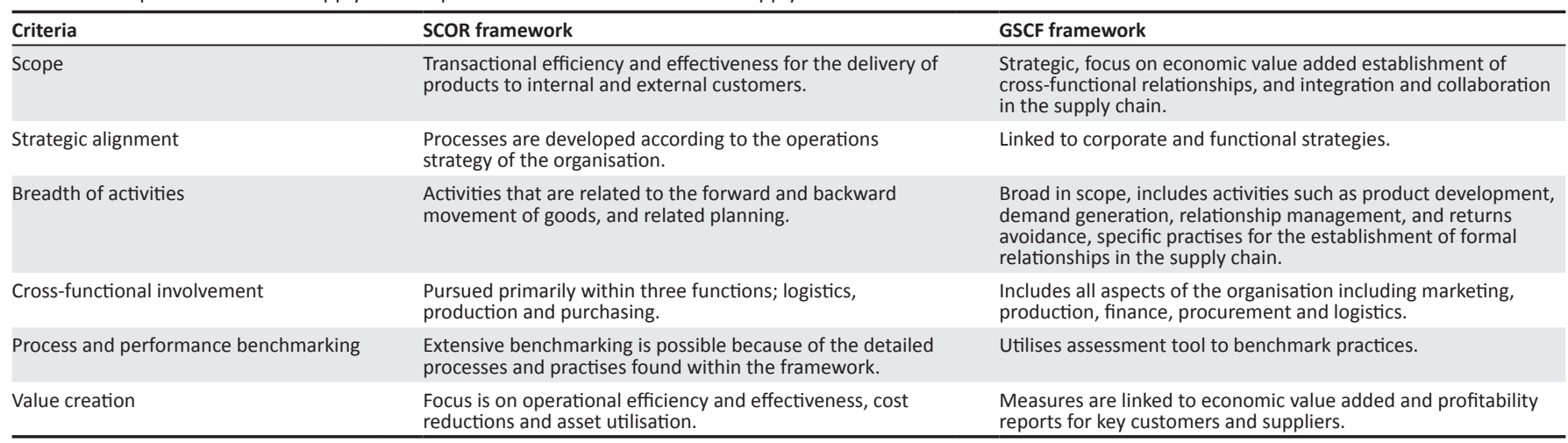

Source: Lambert, D.M., García-Dastugue, S. \& Croxton, K., 2005, 'An evaluation of process-oriented supply chain management frameworks', Journal of Business Logistics 26(1), 25. http://dx.doi.

org/10.1002/j.2158-1592.2005.tb00193.x SCOR, Supply Chain Operations Reference; GSCF, Global Supply Chain Forum 
For the purposes of the case study, the GSCF framework was identified as the SCM framework to be used to study the practices of the South African confectionery manufacturer (the focus of the case study), by virtue of its scope, clear prescription of collaboration and integration practices, description of interorganisational processes, leveraging of supply chain wide learning and knowledge, and the achievement of corporate objectives inclusive of the creation of economic value added (EVA) as its primary aims.

The following section provides a brief overview of the confectionery industry in South Africa within which the selected confectionery company operates.

\section{The South African confectionery industry}

The South African confectionery market is concentrated, with the largest producers in the industry by value accounting for $62.6 \%$ of the revenues in the South African market. These manufactures and their respective market shares are Mondelez 36.1\%, Nestlé 13.5\%, Tiger Brands 13.0\%, and the Kellogg Company 3.3\%. The balance of the market share, accounting for $34.1 \%$, is controlled by small and medium sized (SME) manufacturers and distributors marketing imported products (Marketline 2012:13).

By differentiating products through varying inherent characteristics, investment in well-known brands and a national distribution network, the top manufacturers are able to maintain their market share relative to SME manufacturers and distributors of foreign products. The competitive rivalry is significant amongst the three manufacturers, given the similarity of their customers and products, as well as their use of automated large scale manufacturing, where production capacity increases are possible (facilitated by existing technical knowledge and the availability of capital for investment purposes), and fixed costs are high (Datamonitor 2009:19).

The drivers of rivalry in the confectionery market are the number of manufacturers and distributors, the low cost of switching between suppliers for retailers and consumers, undifferentiated products, ease of expansion, difficultly of exiting the market because of large capital investments, the lack of diversity in product offerings, the similarity of the manufacturers, storage costs that encourage manufacturers to move product to retailers, and relative competitor size (Datamonitor 2009:19).

The South African confectionery industry is therefore a competitive industry with dynamic consumer-led demand and two predominant channels of distribution: independent retailers and supermarket chains. The challenges that the industry forces bring about constantly require South African manufacturers to find ways of maintaining market share and ensuring that they remain competitive in the face of relatively cheap imported products, and new entrants to the market who are motivated by the relative ease of entry.

\section{Research methodology}

The primary objective of the research article was, firstly, to identify a proven SCM best practice framework founded on the principles of supply chain integration and process management and, secondly, to benchmark the SCM practices of a leading South African confectionery manufacturer against the chosen framework. A literature study provided for the achievement of the first objective. The case study method was chosen as the research approach to attain the second objective as it allows for holistic and meaningful characteristics of an individual organisation to be identified and understood within a real-life context, through the observation of complex social phenomena within the context of contemporary events. This research approach is particularly relevant to the study of supply chain management, given the complex and systematic nature of its various elements and interactions amongst functions in an organisation and amongst organisations in a supply chain.

The organisation chosen to be the focus of the study is one of the three largest confectionery manufacturers in the industry as measured by market share, and is a public multinational organisation manufacturing and marketing fast moving consumer goods (FMCG) products. The organisation has local manufacturing capacity and performs manufacturing, marketing, procurement, distribution, and supply chain management functions within South Africa. For confidentiality purposes, the name of the company will not be disclosed.

For the benchmarking exercise, use was made of the GSCF's framework assessment tool that contains a sliding scale of adherence from one to five per activity of each subprocess, contained within each key business process of the framework. A worded justification is required for the level of adherence to the practice indicated per activity. The importance ascribed to each activity is then recorded as being of minor importance, important, or critical.

A discussion was held with the supply chain manager of the organisation to explain the delineation of the processes and activities within the GSCF framework. On the basis of this understanding, the researcher was referred to the respective managers for each of the processes according to the alignment of their functions to the processes.

The research was carried out through a series of face-to-face interviews with the relevant functional heads whose area was closest aligned to each supply chain management process identified in the framework. Each supply chain management process was defined and described to the respondent, and the strategic subprocesses were explained before the assessment with the respective respondents took place. Key terms within the framework, and the context of those terms, were also explained. 
The structure and design of the assessment tool was explained in terms of the statement that most resembles the organisation's current practice, the importance ascribed by the respondent to the activity described, and a justification in the form of a specific explanation and examples of the organisation's current practices to support the answer provided. The researcher ensured that the answers that the respondents provided were valid and accurate by requesting a justification for each response, and crossreferencing responses from previous questions to test for consistency. The interviews took place over a two-month period in 2013 and included managers in charge of supply chain management, supply and demand management, customer service, distribution, product innovation, returns, and procurement. Seven managers were interviewed in total. Only internal employees of the organisation were interviewed.

\section{Research findings}

The use of the GSCF assessment tool allowed for a quantitative scoring on the level of adherence to the practices described in the framework as well as a qualitative description of the findings.

As the GSCF assessment tool consistently reflects adherence to the practice in the framework on a scale from one (no adherence), to five (full adherence), it is possible to reflect the level of adherence as an average per process, as well as the importance ascribed to the activities within each process. Each supply chain management process is broken down into strategic and operational processes and then further broken down into subprocesses, which in turn are made up of a number of activities. It is these activities that are individually assessed using the assessment tool. It is therefore possible to quantify the findings and express them according to the scores reflected in the responses.

The findings of the assessment are reflected by means of scores and percentage adherence achieved per strategic supply chain process (Table 2) and average scores achieved per strategic subprocess (Table 3). Figure 1 depicts the importance ascribed to the activities within each strategic supply chain management process, and Figure 2 depicts the ratio of importance ascribed to all activities within each strategic supply chain management process.

\section{Analysis of the findings}

The findings discussed in this section are based on themes which emerged from the analysis of overall qualitative and quantitative data and which were common to a number of supply chain processes. The findings are not structured to reflect the findings of the individual processes, which are indicated in the tables.

\section{Overall adherence to the best practices within the Global Supply Chain Forum framework was high}

As can be seen in Table 1, the overall adherence of the organisation's supply chain management practices to those described within the GSCF framework were high, even though the organisation does not formally ascribe to the GSCF framework. The average scores achieved per supply chain management process represent a high average score across all the subprocesses, and generally not a combination of low and high scores. When taken as an overall percentage, the level of adherence of the organisation's processes to the framework equals $76 \%$.

\section{A large majority of activities within the processes were considered to be important or critically important}

As can be seen in Figure 2, 94\% of the activities within the strategic processes of the framework were considered to be critical or important by the respondents. This was the case even for activities where adherence to best practice was low. This result suggests the validity of the GSCF framework, at least from the perspective of the respondents. The level of importance ascribed can also be contrasted against the $76 \%$ overall adherence to the practices within the framework in the identification of improvement opportunities and the priority to be assigned to such opportunities.

\section{The supply chain function operates autonomously and on an equal basis with other functional areas}

Across all of the supply chain management processes, with the exception of product development and commercialisation, the management within the supply chain function actively manages the processes and leads other functions within the organisation. This is supported by the supply chain management activities being coordinated by a dedicated

TABLE 2: Scores and percentage adherence achieved per strategic supply chain process according to the Global Supply Chain Forum benchmarking framework.

\begin{tabular}{|c|c|c|c|}
\hline Strategic supply chain process & Score achieved & Possible total score & Percentage adherence $(\%)$ \\
\hline Customer relationship management & 59 & 65 & 91 \\
\hline Supplier relationship management & 47 & 75 & 63 \\
\hline Customer service management & 73 & 85 & 86 \\
\hline Demand management & 75 & 100 & 75 \\
\hline Order fulfilment & 57 & 75 & 76 \\
\hline Manufacturing flow management & 78 & 110 & 71 \\
\hline Product development and commercialisation & 98 & 135 & 73 \\
\hline Returns management & 86 & 105 & 82 \\
\hline Total & 573 & 750 & 76 \\
\hline
\end{tabular}


TABLE 3: Average score achieved per strategic subprocess according to the Global Supply Chain Forum benchmarking framework.

\begin{tabular}{|c|c|}
\hline Strategic subprocess & Average score achieved per strategic subprocess out of 5 \\
\hline Customer relationship management process & 4.66 \\
\hline S-1. Review corporate and marketing strategy & 4 \\
\hline S-2. Identifying criteria for segmenting customers & 5 \\
\hline S-3. Provide guidelines for the degree of customisation in the product and service level agreement & 5 \\
\hline S-4. Develop a framework of metrics & 4.3 \\
\hline S-5. Develop guidelines for sharing process improvement benefits with customers & 5 \\
\hline Supplier relationship management process & 3.4 \\
\hline S-1. Review corporate, marketing, manufacturing and sourcing strategies & 4.5 \\
\hline S-2. Identify criteria for segmenting suppliers & 5 \\
\hline S-3. Provide guidelines for the degree of customisation in the product and service agreement & 2 \\
\hline S-4. Develop a framework of metrics & 2.5 \\
\hline S-5. Develop guidelines for sharing process improvement benefits with suppliers & 3 \\
\hline Customer service management process & 4.28 \\
\hline S-1. Develop customer service strategy & 5 \\
\hline S-3. Develop infrastructure for implementing response procedures & 4.25 \\
\hline S-4. Develop a framework of metrics & 3.25 \\
\hline Demand management process & 3.58 \\
\hline S-1. Determine demand management goals and strategy & 4.33 \\
\hline $\mathrm{S}-2$. Determine forecasting procedures & 4 \\
\hline S-3. Plan information flow & 4.66 \\
\hline S-4. Determine synchronisation procedures & 3 \\
\hline S-5. Develop contingency management system & 2 \\
\hline S-6. Develop a framework of metrics & 3.5 \\
\hline Order fulfilment process & 3.86 \\
\hline S-1. Review corporate and marketing strategy & 3.8 \\
\hline S-2. Define requirements for order fulfilment & 4 \\
\hline S-3. Evaluate logistics network & 4 \\
\hline S-4. Define plan for order fulfilment & 3.75 \\
\hline S-5. Develop a framework of metrics & 3.75 \\
\hline S-2. Determine degree of manufacturing flexibility & 3.4 \\
\hline S-3. Determine push-pull boundaries & 1 \\
\hline S-4. Identify manufacturing constraints and determine capabilities & 4.8 \\
\hline S-5. Develop framework of metrics & 2.5 \\
\hline Product development and commercialisation process & 3.33 \\
\hline S-1. Review corporate, marketing, manufacturing and sourcing strategies & 4 \\
\hline S-2. Develop idea generation and screening rocesses & 2.8 \\
\hline S-3. Establish guidelines for cross-functional product development team membership & 1.66 \\
\hline S-4. Identify product roll-out issues and constraints & 4.2 \\
\hline S-6. Develop framework of metrics & 4 \\
\hline Returns management process & 4.08 \\
\hline S-1. Determine returns management goals and strategy & 4.5 \\
\hline S-2. Develop avoidance, gatekeeping and disposition guidelines & 4.5 \\
\hline S-3. Develop returns network and flow options & 4 \\
\hline S-4. Develop credit rules & 3.66 \\
\hline S-5. Determine secondary markets & 4.33 \\
\hline S-6. Develop framework of metrics & 3.5 \\
\hline
\end{tabular}

Source: Peristeris, O., 2014, 'Supply chain management practices in a leading manufacturing organisation', Master's thesis, Dept. of Transport and Supply Chain Management, University of Johannesburg, viewed 13 June 2015, p. 187, from http://ujdigispace.uj.ac.za/handle/10210/11812

supply chain function within the organisation, with a number of individuals broadly managing each of the supply chain management processes. The supply chain function is also represented at the executive level by a supply chain director.

\section{Extensively developed customer relationship and customer service management processes}

As can be seen in Table 2, the customer facing processes are well developed within the organisation, with the two highest scores achieved being those for the customer relationship management (91\%) and customer service management (86\%) processes. There are extensively developed formal communication and coordination mechanisms in place with key customers, with the clear identification and segmentation of key customers and customer segments, and formally documented procedures for the parameters for the negotiation of agreements with customers. Business relationships are also formally documented in the form of product and 


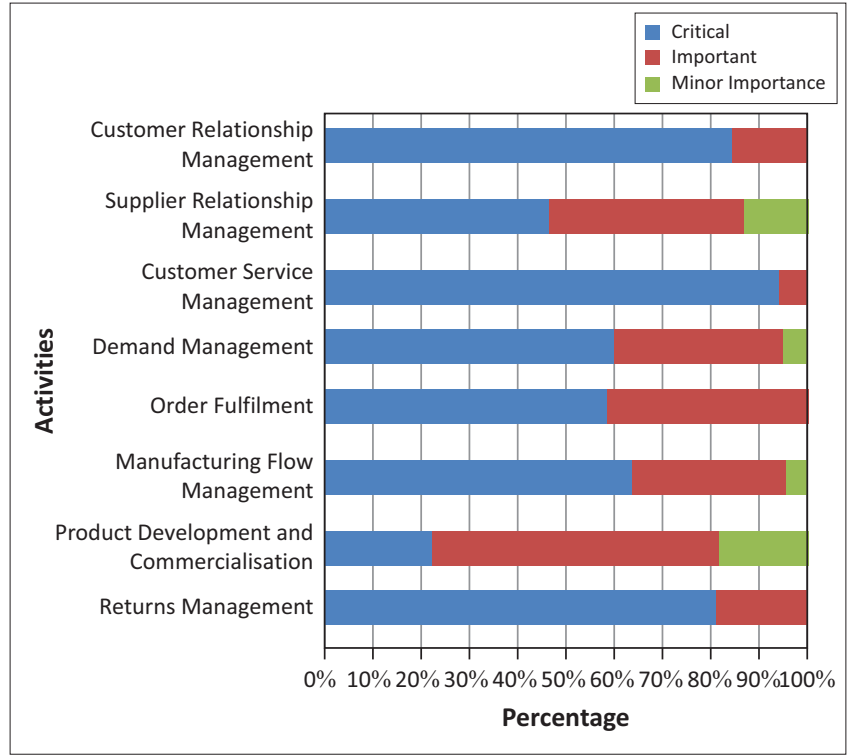

Source: Peristeris, O., 2014, 'Supply chain management practices in a leading manufacturing organisation', Master's thesis, Dept. of Transport and Supply Chain Management, University of Johannesburg, viewed 13 June 2015, p. 154, from http://ujdigispace.uj.ac.za/ handle/10210/11812

FIGURE 1: Importance ascribed to the activities within each strategic supply chain management process.

service agreements and the sharing of improvements from re-engineering and reconfiguration projects and initiatives. The formal discussion and agreement of product and service agreements (PSAs) between senior management of the respective organisations, with cross-functional assistance and input, is the primary integrating mechanism. The extent of business that takes place between the respective organisations serves as the basis for collaboration. Ongoing reviews of joint metrics and performance on the targets ascribed to in the PSAs indicate that there is commitment between the respective organisations to achieving the objectives of set out in the PSAs.

\section{Cross-functional approach to the management of processes}

It was apparent in the responses given by a number of the respondents that there is extensive internal cross-functional involvement in the management of the supply chain management processes within the organisation. Whilst each of the processes is effectively owned by a particular function within the supply chain function, there is a high level of involvement, buy-in and awareness of the activities, metrics, goals, and functioning of each process. There is also extensive involvement from other functions within the organisation, such as sales, legal and regulatory compliance, manufacturing, finance, and the business units that manage different product lines. Collaboration is driven by common objectives, such as order fill-rate and overall profitability. Regular cross-functional meetings and reviews, and documented roles and responsibilities for specific activities drive integration (Peristeris 2014:193).

However, the same level of integration and collaboration is not prevalent with customers and suppliers in activities

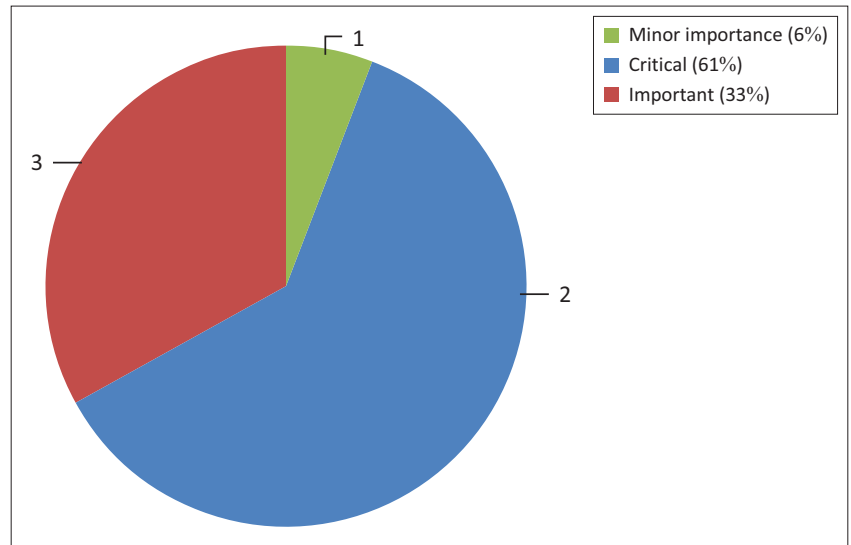

Source: Peristeris, O., 2014, 'Supply chain management practices in a leading manufacturing organisation', Master's thesis, Dept. of Transport and Supply Chain Management, University of Johannesburg, viewed 13 June 2015, p. 154, from http://ujdigispace.uj.ac.za/ handle/10210/11812

FIGURE 2: Ratio of importance ascribed to all activities within each strategic supply chain management process overall.

outside of the customer relationship and supplier relationship management and product development and commercialisation processes. The indication is that certain processes are considered to be the concern of internal functions to determine and formulate, whilst others are naturally externally focused, and by their nature involve integration with customers and suppliers in the supply chain (Peristeris 2014:193).

\section{Business strategies are established and well-known}

The organisation has well developed business strategies for each functional area that communicated effectively throughout the organisation. There is a cascading approach in the implementation of the strategies, with plans and objectives being established for each division, business unit, department and work team level. This creates a high degree of awareness and understanding within the organisation regarding various related strategies and the objectives to be achieved, as well as an awareness of the steps to be taken by each department to achieve the strategies over the various time-periods for the execution of different strategies (Peristeris 2014:193).

\section{Conflicts exist amongst metrics throughout the organisation}

It was indicated in the responses that conflicts such as inventory availability and working capital requirements, manufacturing economies and planning flexibility, volume buying of inputs to production and storage costs, and order cycle time and logistics costs, were reported amongst metrics used within processes and groups of functions, as well as amongst metrics used by specific functions. The respondents to the survey indicated that these conflicts were a normal part of the functioning of the organisation, and whilst they presented challenges to meeting their objectives, they did not represent a fundamental problem within the organisation (Peristeris 2014:193). 


\section{Customers do not understand how their decisions and actions impact on supply chain processes, whilst suppliers do}

Respondents indicated that customers understand their impact on certain supply chain management processes, yet they act in a manner that negatively affects the performance of the supply chain management processes.

On the other hand, suppliers understand their influence on supply chain processes, and their actions normally avoid harming their customers in the supply chain processes in which they have a role to play (Peristeris 2014:195).

\section{Process related procedures are well documented}

The organisation makes extensive use of documented standard operating procedures (SOPs). Each functional area and its related activities had SOP documentation indicating the policies of the organisation, the steps to be followed to carry out tasks, as well as guidelines regarding the options that could be followed in a particular activity. The procedures also covered compliance rules and regulations, which are especially applicable for a food manufacturing company. These kinds of documents were well understood and frequently referred to by different functional heads during the course of the survey process. Ongoing discussion of the effectiveness and validity of processes and revision of the SOP documents takes place or new options or requirements are identified. Employees are also formally trained on the contents of the SOPs, which ultimately leads to standardisation and consistency in the execution of supply chain management activities (Peristeris 2014:196).

Importantly, once the initial decisions on a strategic and tactical level were taken, these documented procedures provided the basis for the implementation, as well as continuous improvement of supply chain management process activities within the organisation on a day-to-day basis (Peristeris 2014:196).

\section{Extensive use of metrics and performance goals}

As can be seen in the scores recorded for the activities related to metrics in Table 3, the organisation makes extensive use of process and financial metrics, and sets performance goals in the management of its supply chain processes and activities. The metrics to be used at each level of the organisation are set out by the corporate headquarters, and a comprehensive process of analysis and discussion takes place at the top management level with the directors of the various divisions and business units establishing the goals that need to be achieved in the respective areas, in order for the organisation to achieve the objectives that have been set by the corporate headquarters for the financial year in terms of revenue, profitability, and growth. At the senior management level, it is also determined which goals and metrics are joint metrics that require the involvement of multiple divisions or departments to be achieved, and the necessary coordination is established. A cascading process of establishing goals at each level with the divisions and departments is then followed. This process of breaking down the goals into more specific goals per department and division and aligning them to each other, enables the achievement of the goals and objectives set at the top level (Peristeris 2014:193).

\section{Supplier relationship management process not fully developed}

As can be seen in Table 3, the organisation has not developed its supplier relationship management process to the extent described in the framework. A number of key activities are not being carried out, such as the drawing up of product and service agreements, profitability reports for suppliers, and formal procedures concerning areas such as sharing of process improvements with suppliers and customisation alternatives for supplier PSAs (Peristeris 2014:197).

The difference in the maturity between the supplier relationship and customer relationship management processes can be partly explained by the emphasis within the organisation on revenue-generating sales and marketing activities, whereby the processes and activities involving interaction with customers are prioritised and developed. Typically, within organisations, the procurement function is viewed as a cost centre and as an input into the manufacturing process, with supplier relationships being adversarial and characterised by negotiations regarding the cost of materials. This approach is especially prevalent in the confectionery industry where the main inputs to production are raw materials with low levels of inherent technology such as sugar, glucose, cocoa, and food additives. This would thus drive a transactional cost-focussed approach to be taken with suppliers, with the capacity of suppliers being assessed, and the capability of suppliers to provide materials meeting the standards required for the manufacturing of food products being the key criteria for selection as suppliers (Peristeris 2014:197).

\section{Overall performance}

As indicated by Table 2, the organisation has a high level of overall performance in terms of the benchmark practices found within the GSCF framework. This performance includes the organisation's capacity to supply large volumes of product to a growing market, the maintenance of relationships with the largest national retail chains and wholesale retailers, financial performance, reputation for food quality and safety, the strength of its brands in the market, high levels of customer service and logistical execution performance, and innovation in new product development. Ultimately, this can be largely attributed to the development and implementation of supply chain management processes and the extensive use of procedures, methodologies, metrics, and performance goals that drive the achievement of the organisation's objectives (Peristeris 2014:198).

\section{Conclusion and recommendations}

Supply chain management is uniquely placed to enable organisations to achieve sustainable competitive advantage as a result of its encompassing nature and its basis of 
collaboration and integration between an organisation and its key customers and suppliers.

The literature study combined with a case study benchmarking exercise provided two main findings. Firstly, the results indicate that the GSCF framework represents a common sense approach to best practice supply chain management, with a high level of relevance and applicability to the South African environment. The GSCF framework provides a detailed definition and description of supply chain management and how it is to be implemented in practice, by outlining the processes, strategic and operational subprocesses, and activities which, when carried out in a collaborative environment through a cross-functional approach, allow for the effective management of the supply chain, and the realisation of the benefits that typically arise from it.

The GSCF framework is a useful tool that can be used by manufacturers within the FMCG industry to analyse existing supply chain management practices, and implement processes according to the framework. The framework also has relevance for retailers and distributors within the industry in that they can develop an understanding of their role in the supply chain, how to facilitate collaboration, drive the integration of processes, and actively participate in practices outlined in the framework, which will ultimately benefit the FMCG supply chain as a whole.

Secondly, it indicated that best practices described within the GSCF framework are being comprehensively applied by a major, competitive FMCG manufacturer within the South African confectionery industry. This includes extensive integration and collaboration with customers and suppliers, the formal recognition and documenting of supply chain management activities and procedures, a cross-functional approach to the management of processes, extensive measurement of activities, and clearly defined strategies within each area of the supply chain management function within the organisation (Peristeris 2014).

Regular reviews of SCM practices coupled with deliberate improvement strategies is necessary for organisations to compete effectively in competitive business environments. The utilisation of proven best practice frameworks such as the GSCF framework can provide much needed guidelines in the process. Further studies linked to the GSCF framework are required to test its applicability to the processes of organisations upstream or downstream of the manufacturing entity in the confectionery and other industries.

\section{Limitations of the study}

The first limitation of the study is the focus on a single large South African confectionery manufacturer as the respondent and focus of the study. The results of the study will therefore only be applicable to this manufacturer, and cannot be generalised as an industry characteristic.

A second limitation is the use of a single supply chain management best practice framework (the GSCF framework) as the means of benchmarking the supply chain management processes of the chosen company.

Furthermore, the research only focussed on the strategiclevel supply chain processes, tasks, based on the chosen best practice framework, and thus precluded, and analysis of the operational level supply chain processes and tasks.

The research also did not interview external parties to measure their perspectives of the integration of the processes across the supply chain.

\section{Acknowledgements Competing interests}

The authors declare that they have no financial or personal relationships, which may have inappropriately influenced them in writing this article.

\section{Authors' contributions}

O.P. (Value Logistics) conducted the literature review, primary research, documented the findings, and wrote the article from the findings of his M.Com Logistics Management dissertation at the University of Johannesburg and, P.J.K. (University of Johannesburg) acted as the supervisor of the dissertation, and made technical and content revisions and additions to the article, J.W. (University of Johannesburg) reviewed the article and made technical and content suggestions, revisions and additions.

\section{References}

Bagchi, P.K., Chun Ha, B., Skjoett-Larsen, T. \& Soerensen, L.B., 2005, 'Supply chain integration: A European survey', The International Journal of Logistics Management 16(2), 275-294. http://dx.doi.org/10.1108/09574090510634557

Chen, H., Daugherty, P.J. \& Roath, A.S., 2009, 'Defining and operationalising supply chain process integration', Journal of Business Logistics 30(1), 63-84. http:// dx.doi.org/10.1002/j.2158-1592.2009.tb00099.x

Council of Supply Chain Management Professionals, 2014, CSCMP supply chain management definitions, viewed 07 April 2010, from http://cscmp.org/ aboutcscmp/definitions.asp

Datamonitor, 2009, Confectionery in South Africa industry profile, viewed 02 February 2010, from http://0-www.marketlineinfo.com.ujlink.uj.ac.za

Fawcett, S.E., Magnan, G.M. \& McCarter, M.W., 2008, 'Benefits, barriers, and bridges to effective supply chain management', Supply Chain Management: An International Journal 13(1), 35-48. http://dx.doi.org/10.1108/13598540810850300

Kim, S.W., 2006, 'Effect of supply chain management practices', Supply Chain Management: An International Journal 11(3), 241-248. http://dx.doi. org/10.1108/13598540610662149

Lambert, D., Cooper, M. \& Pagh, M., 1998, 'Supply chain management: Implementation issues and research opportunities', The International Journal of Logistics Management 9(2), 1-19. http://dx.doi.org/10.1108/09574099810805807

Lambert, D.M., 2008, 'Supply chain management', in D.M. Lambert (ed.), Supply chain management: Processes, partnerships, performance, 3rd edn., p. 2, Supply Chain Management Institute, Sarasota.

Lambert, D.M., García-Dastugue, S. \& Croxton, K., 2005, 'An evaluation of processoriented supply chain management frameworks', Journal of Business Logistics 26(1), 25-51. http://dx.doi.org/10.1002/j.2158-1592.2005.tb00193.x

Lin, M.J.J. \& Chen, C.J., 2008, 'Integration and knowledge sharing: Transforming to long term competitive advantage', International Journal of Organizational Analysis 16(1/2), 83-108. http://dx.doi.org/10.1108/19348830810915514

Marketline, 2012, Confectionery in South Africa, viewed 18 August 2013, from http://0-www.marketlineinfo.com.ujlink.uj.ac.za

Peristeris, O., 2014, 'Supply chain management practices in a leading manufacturing organisation', Master's thesis, Dept. of Transport and Supply Chain Management, University of Johannesburg, viewed 13 June 2015, from http://ujdigispace.uj.ac. za/handle/10210/11812

Poluha, R.G., 2007, Application of the SCOR model in supply chain management, Cambria Press, New York. 
Porter, M.E., 1985, Competitive advantage: Creating and sustaining superior performance, Free Press, New York.

Ritala, P. \& Ellonen, H.K., 2010, 'Competitive advantage in interfirm cooperation: Old and new explanations' Competitiveness Review: An International Business Journal 20(5), 367-383. http://dx.doi.org/10.1108/10595421011080751

Stock, J.R. \& Boyer, S.L., 2009, 'Developing a consensus definition of supply chain management: A qualitative study', International Journal of Physical Distribution \& Logistics Management 39(8), 690-711. http://dx.doi.org/10.1108/09600030 910996323
Supply Chain Council, 2011, Supply chain operations reference (SCOR) model overview version 10.0, Supply Chain Council, TX.

Tracey, M., Lim, J.S. \& Vonderembse, M.A., 2005, 'The impact of supply-chain management capabilities on business performance', Supply Chain Management: An International Journal 10(3), 179-191. http://dx.doi.org/10.1108/135985405 10606232

Zailani, S. \& Rajagopal, P., 2005, 'Supply chain integration and performance: US versus East Asian companies', Supply Chain Management: An International Journal 10(5), 379-393. http://dx.doi.org/10.1108/13598540510624205 